\title{
Divergent Effects of TNF $\alpha$ in the Adoptive Immunotherapy of a Murine Sarcoma
}

\author{
Paul D. Wagner, B.S., Suyu Shu, Ph.D., and Alfred E. Chang, M.D. ${ }^{1}$ \\ Division of Surgical Oncology, University of Michigan, Ann Arbor, Michigan 48109 \\ Submitted for publication March 21, 1991
}

We have previously described an in vitro sensitization (IVS) procedure which enabled the generation of therapeutic $T$ cells from tumor-bearing mice for adoptive immunotherapy. The procedure involved culture of tumor-draining lymph node (TDLN) cells with irradiated tumor in the presence of interleukin-2 (IL-2). The availability of many recombinant cytokines affords an opportunity to examine their effects on the immune response to tumor. In this study, we investigated the effect of tumor necrosis factor- $\alpha$ (TNF $\alpha$ ) on the generation and function of IVS cells utilized in adoptive immunotherapy of the murine MCA 106 sarcoma. TNF $\alpha$ administered iv at nontherapeutic doses was found to enhance the antitumor efficacy mediated by IVS cells plus IL-2 in the treatment of pulmonary metastases. In contrast, $\mathrm{TNF} \alpha$ administration to mice bearing progressive footpad tumors had inhibitory effects on the sensitization of tumor-reactive cells in TDLN since IVS cells generated from these animals displayed a diminished antitumor effect. This effect appeared to be due to a reduced number of tumor-reactive lymphoid cells in the TDLN since TNF $\alpha$ added to IVS cultures did not alter the antitumor efficacy of the resultant IVS effector cells. These findings indicate the divergent effects of TNF $\alpha$ on the immune response to tumor and adoptive immunotherapy with IVS cells. (c) 1992 Academic Press, Inc.

\section{INTRODUCTION}

Adoptive immunotherapy with sensitized T lymphocytes can mediate the regression of established tumor in a variety of animal models [1-3]. These observations have formed the rationale to evaluate this approach in the treatment of human cancer. However, there are two major obstacles that need to be overcome in developing adoptive immunotherapeutic strategies in man. Foremost is the need to reliably isolate effector cells capable

\footnotetext{
${ }^{1}$ To whom correspondence should be addressed at Division of Surgical Oncology, University of Michigan Medical Center, 1500 E. Medical Center Drive, Ann Arbor, MI 48109.
}

of mediating tumor regression from the cancer patient. Secondly, methods to expand large numbers of antitumor effector cells for clinical therapy are required. We have identified an in vitro sensitization (IVS) method with which therapeutic $\mathrm{T}$ lymphoid cells from mice bearing progressively growing tumors can be generated in large quantities $[4,5]$. This method involves the stimulation of TDLN cells with irradiated tumor in the presence of IL-2. We have reported that, in the absence of IVS, fresh TDLN cells did not mediate tumor regression after adoptive transfer; however, during IVS culture these cells differentiated into potent therapeutic effector cells. Since therapeutic IVS effector cells cannot be generated from lymphoid cells of normal animals, progressive tumor growth must stimulate an immune response within the host. We have termed these lymphoid cells, "preeffector" cells. Using these principles, we are currently evaluating the tumor reactivity of human IVS cells in a clinical trial [6].

Experimentally, tumor regression mediated by adoptively transferred $\mathrm{T}$ effector cells is dose related. To date, clinical experience of adoptive immunotherapy in man has been logistically cumbersome and labor intensive in order to generate large numbers of effector cells for therapy. Nevertheless, initial results from these studies have provided optimism that the theoretical basis of this approach has clinical utility $[7,8]$. Current investigations are being directed to isolate more potent antitumor reactive cells (i.e., tumor-specific $\mathbf{T}$ cells) or enhance their in vivo function. Our adoptive immunotherapy animal model involves three distinct steps: (1) elicitation of preeffector cells in the tumor-bearing host, (2) in vitro differentiation and expansion of therapeutic cells in IVS culture, and (3) mediation of tumor regression by IVS cells after adoptive transfer. We have examined the effect of $\mathrm{TNF} \alpha$ within each of these components to determine if $\mathrm{TNF} \alpha$ may be a useful adjunct.

$\mathrm{TNF} \alpha$ is primarily a macrophage product which was described by its ability to induce hemorrhagic necrosis and regression of some solid tumors $[9,10]$. TNF $\alpha$ has also been found to have multiple immunomodulating properties which make it relevant for study in enhancing the host immune response to tumor. $\mathrm{TNF} \alpha$ has been 
shown to activate neutrophils and macrophages; enhance natural killer activity; upregulate tumor cell surface antigen expression; upregulate IL-2 receptor expression; and enhance the generation of cytotoxic $T$ lymphocytes to tumor immunization [11-15]. In this report, we have examined the effects of TNF $\alpha$ in the generation of preeffector lymphocytes as well as in adoptive immunotherapy utilizing the weakly immunogenic MCA 106 murine sarcoma. We found that administration of TNF $\alpha$ during progressive tumor growth inhibited the development of preeffector cells. However, TNF $\alpha$ was found to enhance the antitumor efficacy of IVS cells for adoptive immunotherapy.

\section{MATERIALS AND METHODS}

Mice. Female C57BL/6J (B6) mice, 8 to 12 weeks old, were obtained from the Jackson Laboratory (Bar Harbor, ME). Caged in groups of six or fewer, the animals were fed laboratory chow and were given water ad libitum.

Tumor. The MCA 106 sarcoma is a methylcholanthrene-induced tumor of $\mathrm{B} 6$ origin. A large number of vials of this tumor from the first passage generation were cryopreserved. After thawing from storage, this tumor was transplanted by subcutaneous (sc) inoculation in syngeneic mice and always used within the first seven transplant generations. Single-cell suspensions were prepared from solid tumors by digestion with constant stirring in $40 \mathrm{ml}$ of Hanks' balanced salt solution (HBSS) (GIBCO, Grand Island, NY) containing $4 \mathrm{mg}$ deoxyribonuclease, $40 \mathrm{mg}$ collagenase, and $100 \mathrm{U}$ hyaluronidase (Sigma Chemical Co., St. Louis, MO) for $3 \mathrm{hr}$ at room temperature [4].

For establishing solid tumors, B6 mice were inoculated sc in the footpad with $5 \times 10^{5}$ to $10^{6}$ MCA 106 sarcoma cells in $0.05 \mathrm{ml}$ of HBSS. The growth of tumors was evident on Day 3 and, if allowed to grow, all animals would eventually succumbed to the progressively growing tumor with a median survival time of approximately 23 days.

TDLN cell suspensions. Popliteal lymph node draining sites of growing tumor were removed asceptically. Single-cell suspensions were prepared mechanically by pressing the blunt end of a $10-\mathrm{ml}$ plastic syringe plunger in HBSS. The cell suspension was filtered through a layer of No. 100 nylon mesh, (Nytex, TETKO Inc., Briarcliff Manor, NY), washed twice, and suspended in appropriate medium for culture.

Recombinant cytokines. Recombinant human TNF $\alpha$ and recombinant human IL-2 were generously provided by the Cetus Corp. (Emeryville, CA). TNF $\alpha$ had a specific activity of $2.2 \times 10^{7}$ units/mg as determined by the murine L929 cytolytic bioassay and had an endotoxin level of $0.2 \mathrm{ng} / 2.2 \times 10^{7}$ units of TNF $\alpha$ measured by the standard Limulus assay. In vivo administration of
'TNF $\alpha$ was via intravenous (iv) injection into the tail vein in $1.0 \mathrm{ml}$ of HBSS contain $0.2 \%$ of pooled normal mouse serum.

Purified IL-2 had a specific activity of $3 \times 10^{6}$ Cetus units $/ \mathrm{mg}$ and an endotoxin level of $<0.1 \mathrm{ng} / 10^{6}$ units of IL-2 as measured by the standard Limulus assay. One Cetus unit of IL-2 is equivalent to 6 international units. All units of IL-2 in this report are expressed in Cetus units.

IVS of lymphoid cells with tumor cells and IL-2. The procedures for IVS have been detailed previously (4). Briefly, $6 \times 10^{5}$ lymph node cells were cultured with $10^{5}$ MCA 106 irradiated (4000R) tumor cells in the presence of $10 \mathrm{U} / \mathrm{ml}$ recombinant IL-2 in $2 \mathrm{ml}$ of complete medium (CM) in 24-well plates. The composition of CM has been described elsewhere (4). The cultures were incubated at $37^{\circ} \mathrm{C}, 5 \% \mathrm{CO}_{2}$, and were fed with $1.0 \mathrm{ml}$ of CM containing $10 \mathrm{U} / \mathrm{ml}$ of recombinant IL-2 approximately 5 days later. These cells were routinely harvested on Days 9-11 when they grew to a high density. These cells were washed three times before resuspending in HBSS for adoptive immunotherapy.

Adoptive immunotherapy model. B6 mice were injected iv with $8 \times 10^{5} \mathrm{MCA} 106$ sarcoma cells in $1.0 \mathrm{ml}$ HBSS to establish pulmonary metastases. On Day 3 or 4, when multiple foci of pulmonary metastases were microscopically evident, therapy was instituted with IVS lymphoid cells given in $1.0 \mathrm{ml}$ of HBSS through the tail vein. Mice were also injected intraperitoneally (ip) with recombinant IL-2 $(7500 \mathrm{U})$ in $0.5 \mathrm{ml}$ of HBSS, twice a day for 3 to 4 days starting on the day of cell transfer. In all experiments, at least five mice were included in each treatment group. At Days 14 to 16 after tumor inoculation, the micc were car-tagged, randomized, and then sacrificed for enumeration of metastatic pulmonary nodules as previously described [16]. Metastases of the sarcoma form white nodules on the blackened surface of the lung (insufflated with a $15 \%$ solution of India ink) when "bleached" by Fekette's solution. Nodules were counted in a double-blind fashion without knowledge of the treatment of that mouse. Mice with metastatic foci too numerous to count were assigned an arbitrary value of $\geqslant 250$ because this was the largest number of nodules that could be reliably enumerated per lung.

Statistics. The Wilcoxon rank test was used to determine the significance of differences in numbers of pulmonary metastases between treatment groups. Twosided $P$ values are presented. No mice were excluded from the statistical evaluation.

\section{RESULTS}

Effect of TNF $\alpha$ on the Development of Preeffector Cells in the Tumor-Bearing Host

B6 mice were inoculated with viable MCA 106 tumor cells in the footpad. Fourteen days later, varying doses of $\mathrm{TNF} \alpha(0.5,2.0,8.0 \mu \mathrm{g})$ were administered iv when the 
TABLE 1

TNF $\alpha$ Administration in Mice with MCA 106 Footpad Tumors: Tumor Size and TDLN Cell Yield

\begin{tabular}{cccccc}
\hline & \multicolumn{2}{c}{ Expt $1^{b}$} & & \multicolumn{2}{c}{ Expt 2 } \\
\cline { 2 - 3 } \cline { 5 - 6 } TNF $\alpha(\mu \mathrm{g})^{a}$ & Tumor size & TDLN & & Tumor size & TDLN \\
\hline 0 & $6.9(0.3)$ & 3.1 & $6.2(0.6)$ & 3.1 \\
0.5 & $6.6(0.2)$ & 4.1 & & $5.9(0.9)$ & 2.6 \\
2.0 & $6.0(0.2)$ & 3.0 & & $5.5(0.6)$ & 2.5 \\
8.0 & $5.1(0.2)^{c}$ & 2.4 & & $5.0(0.6)$ & 1.7 \\
\hline
\end{tabular}

a TNF $\alpha$ administered iv 14 days after inoculation of $5 \times 10^{5} \mathrm{MCA}$ 106 tumor cells in the footpad. Mean (SEM) tumor sizes at this time were $5.7(0.1)$ and $5.4(0.3) \mathrm{mm}$ for Experiments 1 and 2, respectively.

${ }^{b}$ Five days after $\mathrm{TNF}_{\alpha}$ administration tumor size (SEM) in millimeters was measured and TDLN were harvested. TDLN represents average number of cells $\left(\times 10^{7}\right)$ per node.

' $P<.05$ compared to the group that did not receive $\mathrm{TNF} \alpha$.

footpad tumors measured approximately $5-6 \mathrm{~mm}$ in diameter (Table 1). Five days after $\mathrm{TNF} \alpha$ administration, TDLN preeffector cells were harvested for IVS culture. At $8 \mu \mathrm{g} \mathrm{TNF} \alpha$, significant tumor regression in the footpads was observed compared to control animals; and was associated with a decreased TDLN cell yield per node (Table 1). We have previously shown that TDLN preeffector cells are not capable of mediating tumor regression when freshly harvested and require IVS culture to acquire therapeutic efficacy. Therefore, in order to assess for the development of preeffector cells, TDLN cells were cultured by the IVS method and subsequently assayed for antitumor activity in adoptive immunotherapy experiments.

After IVS culture, cells were adoptively transferred into mice bearing 3-or 4-day established pulmonary metastases (Table 2). Low dose IL-2 was administered ip in conjunction with IVS cells since it has been previously shown to facilitate in vivo proliferation of the transferred cells $[17,18]$. These doses of IL-2 alone did not mediate antitumor effects. In order to assess differences in preeffector cell activity between groups of animals, IVS effector cells were adoptively transferred at various doses. Preeffector cells from mice not treated with TNF $\alpha$ were capable of differentiating into potent IVS cells as seen in Table 2. However, there was significant inhibition of preeffector cell activity in all groups of animals receiving TNF $\alpha$. The lowest dose of TNF $\alpha, 0.5 \mu \mathrm{g}$, resulted in diminished preeffector cell activity compared to animals not receiving $\mathrm{TNF} \alpha$. There was no apparent difference in the amount of inhibition with the higher doses of $T N F \alpha$.

A kinetic study of the TNF $\alpha$ effect on preeffector cell activity was performed (Table 3). On Days 7, 11, and 14 after tumor inoculation, $2 \mu \mathrm{g} \mathrm{TNF} \alpha$ was administered iv, and TDLN harvested for IVS culture on Day 20. Subsequent IVS cells were assessed for antitumor reactivity in the adoptive immunotherapy of 3-day pulmonary me- tastases. There was increasing suppression of preeffector cell activity the later the TNF $\alpha$ was administered.

\section{Effect of TNF $\alpha$ on the Differentiation of Preeffector Cells during IVS Culture}

We have shown that preeffector cells mature into functional antitumor effector cells during IVS culture. The antitumor reactivity of IVS cells in adoptive immunotherapy can be enhanced by altering the IL- 2 concentration in the IVS culture [19]. Low concentrations of IL-2 $(2-10 \mathrm{U} / \mathrm{ml})$ resulted in more potent IVS effector cells on a per cell basis than cells cultured in high concentrations of IL-2 (100-1000 U/ml). We examined whether the functional antitumor reactivity of preeffector cells would be altered by the addition of TNF $\alpha$ in the IVS culture system. Preeffector cells were harvested from mice bearing MCA 106 footpad tumor initiated 15 days earlier and placed in IVS culture. TNF $\alpha$ was added at various concentrations $(10,100,1000 \mathrm{U} / \mathrm{ml})$ at the initiation of the IVS cultures which also included a standard concentration of IL-2 $(10 \mathrm{U} / \mathrm{ml})$. IVS cells generated without added $\mathrm{TNF} \alpha$ expanded 1.2-fold over 11 days. IVS cells generated at 10,100 , and $1000 \mathrm{U} / \mathrm{ml}$ of TNF $\alpha$ expanded 1.8-, 1.6-, and 0.9 -fold during this same time interval. The IVS cells were then assayed for antitumor efficacy by the adoptive immunotherapy of 3-day

\section{TABLE 2}

Preeffector Cell Activity in the Tumor-Bearing Host after TNF $\alpha$ Administration

\begin{tabular}{|c|c|c|c|}
\hline \multirow[b]{2}{*}{ IVS Cells } & \multirow[b]{2}{*}{$\mathrm{TNF} \alpha^{a}$} & \multicolumn{2}{|c|}{$\begin{array}{l}\text { Mean pulmonary metastases } \\
\qquad(\mathrm{SEM})^{b}\end{array}$} \\
\hline & & Expt 1 & Expt 2 \\
\hline$\ldots$ & - & $168(29)$ & $227(12)$ \\
\hline $8 \times 10^{6}$ & - & $18(12)^{c}$ & $8(4)^{c}$ \\
\hline $2 \times 10^{6}$ & - & $20(8)^{c}$ & $104(39)$ \\
\hline $0.5 \times 10^{6}$ & - & $101(31)$ & $183(37)$ \\
\hline $8 \times 10^{6}$ & 0.5 & $117(32)$ & $57(17)^{c}$ \\
\hline $2 \times 10^{6}$ & 0.5 & $129(46)$ & $166(25)$ \\
\hline $0.5 \times 10^{6}$ & 0.5 & $153(39)$ & $97(37)$ \\
\hline $8 \times 10^{6}$ & 2.0 & $98(27)$ & $102(24)^{c}$ \\
\hline $2 \times 10^{6}$ & 2.0 & $172(25)$ & $163(33)$ \\
\hline $0.5 \times 10^{6}$ & 2.0 & $135(44)$ & $237(13)$ \\
\hline $8 \times 10^{6}$ & 8.0 & $103(14)$ & $133(35)$ \\
\hline $2 \times 10^{6}$ & 8.0 & $140(28)$ & $179(19)$ \\
\hline $0.5 \times 10^{6}$ & 8.0 & $194(25)$ & $145(35)$ \\
\hline
\end{tabular}

${ }^{a} \mathrm{TNF}_{\alpha}(\mu \mathrm{g})$ administered iv in mice bearing 14-day-established MCA 106 footpad tumors. TDLN were harvested 5 days later for IVS culture.

${ }^{b}$ IVS cells were transferred iv into mice bearing 3-day established MCA 106 pulmonary metastases. All mice received $7500 \mathrm{U}$ IL-2 ip twice daily for six doses commencing with the adoptive transfer of IVS cells.

${ }^{c} P<0.05$ compared to the group that did not receive IVS cells. 
WAGNER, SHU, AND CHANG: TNF $\alpha$ IN ADOPTIVE IMMUNOTHERAPY

TABLE 3

Kinetics of TNF $\alpha$ Inhibition on Preeffector Cell Activity

\begin{tabular}{ccc}
\hline IVS Cells $^{a}$ & $\begin{array}{c}\text { Day of } \\
\text { TNF }^{b}\end{array}$ & $\begin{array}{c}\text { Mean pulmonary } \\
\text { metastases (SEM) }\end{array}$ \\
\hline- & - & $\geq 250$ \\
+ & - & $8(2)^{c}$ \\
+ & 7 & $14(5)^{c}$ \\
+ & 11 & $20(5)^{c}$ \\
+ & 14 & $98(52)$ \\
\hline
\end{tabular}

${ }^{a}$ IVS cells were generated from mice inoculated with $5 \times 10^{5} \mathrm{MCA}$ 106 in the footpad. TDLN cells were harvested 20 days after tumor inoculation. After IVS culture, $8 \times 10^{6}$ cells were transferred iv into mice bearing 3-day-established MCA 106 pulmonary metastases. All mice received $7500 \mathrm{U}$ IL-2 ip twice daily for six doses commencing with the adoptive transfer of IVS cells.

${ }^{b}{ }^{T} \mathrm{TNF} \alpha(2 \mu \mathrm{g})$ was administered iv on different days after tumor inoculation.

${ }^{c} P<0.05$ compared to the group that did not receive IVS cells.

established pulmonary metastases (Table 4). Varying doses of IVS cells were adoptively transferred to assay the relative antitumor efficacy of each group of effector cells. There was no difference in the therapeutic efficacy of IVS cells cultured with $\mathrm{TNF} \alpha$. Although $\mathrm{TNF} \alpha$ administration was found to inhibit in vivo preeffector cell activity, it did not enhance or inhibit the generation of effector cells from preeffector cells during IVS.

\section{TABLE 4}

Effect of TNF $\alpha$ on the in Vitro Generation of IVS Cells

\begin{tabular}{ccc}
\hline IVS Cells $^{a}$ & ${\text { TNF } \alpha^{b}}^{b}$ & $\begin{array}{c}\text { Mean pulmonary } \\
\text { metastases (SEM) }\end{array}$ \\
\hline- & - & $128(37)$ \\
$6 \times 10^{6}$ & - & $2(1)^{c}$ \\
$1.5 \times 10^{6}$ & - & $27(7)^{c}$ \\
$3.8 \times 10^{5}$ & - & $121(22)$ \\
$6 \times 10^{6}$ & 10 & $2(<1)^{c}$ \\
$1.5 \times 10^{6}$ & 10 & $77(36)$ \\
$3.8 \times 10^{5}$ & 10 & $150(30)$ \\
$6 \times 10^{6}$ & 100 & $5(2)^{c}$ \\
$1.5 \times 10^{6}$ & 100 & $28(5)^{c}$ \\
$3.8 \times 10^{5}$ & 100 & $123(29)$ \\
$6 \times 10^{6}$ & 1000 & $8(3)^{c}$ \\
$1.5 \times 10^{6}$ & 1000 & $67(16)$ \\
$3.8 \times 10^{5}$ & 1000 & $144(51)$ \\
\hline
\end{tabular}

${ }^{a}$ Mice inoculated with $5 \times 10^{5}$ MCA 106 in the footpad and TDLN cells harvested 15 days later for IVS culture. IVS cells were transferred iv into mice with established 3-day MCA 106 pulmonary metastases. All mice received $7500 \mathrm{U}$ IL-2 ip twice daily for six doses commencing with the adoptive transfer of IVS cells.

${ }^{b} \mathrm{TNF} \alpha$ was added to IVS cultures at: $1,10,100$, and $1000 \mathrm{U} / \mathrm{ml}(1 \mathrm{U}$ $=4.55 \times 10^{-5} \mu \mathrm{g} \mathrm{TNF} \alpha$ ).

${ }^{c} P<0.05$ compared to the group that did not receive IVS cells.

TABLE 5

\section{Effect of TNF $\alpha$ Administration on the Antitumor Efficacy of IVS Cells Plus IL-2}

\begin{tabular}{|c|c|c|c|c|c|}
\hline \multicolumn{3}{|c|}{ Treatment } & \multicolumn{3}{|c|}{$\begin{array}{l}\text { Mean pulmonary metastases } \\
\text { (SEM) }\end{array}$} \\
\hline IVS Cells $^{a}$ & IL-2 & $\mathrm{TNF} \alpha^{b}$ & Expt 1 & Expt 2 & $\operatorname{Expt} 3^{c}$ \\
\hline- & + & - & $\geq 250$ & $\geq 250$ & $\geq 250$ \\
\hline- & + & + & $\geq 250$ & $245(5)$ & $221(13)$ \\
\hline $6 \times 10^{6}$ & + & - & $10(5)^{d}$ & $1(1)^{d}$ & $62(23)^{d}$ \\
\hline $1.5 \times 10^{6}$ & + & - & $104(7)^{d}$ & $21(13)^{d}$ & $244(6)$ \\
\hline $6 \times 10^{6}$ & + & + & $1(1)^{e}$ & $1(1)^{e}$ & $18(14)^{e}$ \\
\hline $1.5 \times 10^{6}$ & + & + & $16(8)^{e, f}$ & $2(1)^{e}$ & $174(40)$ \\
\hline
\end{tabular}

${ }^{a}$ IVS cells were administered iv into mice with 3-day-established pulmonary metastases. All mice received IL-2 $7500 \mathrm{U}$ ip twice daily for six doses commencing with the adoptive transfer of IVS cells.

${ }^{b} \mathrm{TNF} \alpha$ was administered iv at 4,2 , and $2 \mu \mathrm{g}$ on the day of adoptive cell transfer in Experiments 1, 2, and 3, respectively.

${ }^{\circ}$ Experiment 3 involves therapy of 3-day MCA 203 pulmonary metastases by IVS cells $\left(5 \times 10^{5}, 1.25 \times 10^{5}\right)$ derived from MCA 203 tumor-bearing mice. IVS culture and adoptive immunotherapy were performed in a manner similar to that of Experiments 1 and 2.

${ }^{d} P<0.05$ compared to the group that received IL- 2 only.

${ }^{e} P<0.05$ compared to the group that received IL-2 and TNF $\alpha$.

${ }^{f} P<0.05$ compared to the group that received IVS cells and IL-2.

\section{Effect of TNF $\alpha$ on the Antitumor Activity of Adoptively Transferred IVS Cells}

We have shown that exogenous IL-2 given ip will enhance the antitumor efficacy of transferred IVS cells [4]. The enhancing effect of IL-2 has been shown to be due to increased proliferation and survival of the transferred cells [18]. We examined the effect of TNF $\alpha$ administration on the therapeutic efficacy of IVS cells plus IL-2 treatment of MCA 106 pulmonary metastases (Table 5). TNF $\alpha(2-4 \mu \mathrm{g})$ was administered iv in conjunction with the transferred cells. These doses of TNF $\alpha$ were nontherapeutic in mediating regression of pulmonary metastases. In mice receiving IVS cells plus IL-2 there was significant regression of pulmonary metastases which was proportional to the number of cells. The addition of TNF $\alpha$ enhanced the antitumor efficacy mediated by the IVS cells plus IL-2.

\section{DISCUSSION}

Studies demonstrating that neoplastic cells express antigens capable of inducing tumor-specific immune responses has provided the rationale for developing immunotherapeutic approaches to cancer. Experimentally, the adoptive transfer of immune $T$ cells has resulted in significant tumor regression and cures in animals with advanced visceral tumors. Once cured, these animals often exhibit systemic tumor immunity by the rejection of subsequent tumor challenges. We have developed a 
method to generate sensitized $\mathrm{T}$ cells from tumor-bearing hosts which mediate potent antitumor effects in adoptive immunotherapy. This method involves the in vitro sensitization of TDLN cells with irradiated tumor in the presence of IL-2 $[4,5]$. The therapeutic efficacy of these IVS cells has been found to be dose dependent. Currently, we are investigating the tumor reactivity of similarly generated cells in a clinical trial [6]. Earlier clinical studies involving lymphokine-activated killer (LAK) cells or tumor-infiltrating lymphocytes (TIL) have utilized $10^{10}$ to $10^{11}$ activated cells $[7,8]$. These efforts have proven to be very labor intensive and difficult. Therefore, methods to enhance the generation or antitumor reactivity of effector $\mathrm{T}$ cells has been an area of active investigation.

The availability of recombinant cytokines has enabled investigators to modulate in vitro and in vivo immune responses. We sought to evaluate the adjuvant effect of TNF $\alpha$ in enhancing the tumor reactivity of T cells in our adoptive immunotherapy model. Besides its tumoricidal activity, TNF $\alpha$ is a cytokine which has diverse immunomodulatory effects. TNF $\alpha$ has been reported to activate neutrophils and macrophages; enhance natural killer and LAK cell activity; upregulate MHC and tumor-associated antigen expression; upregulate intercellular adhesion cell surface molecules; and increase IL-2 receptor expression [11-15, 20]. In addition, $\mathrm{TNF}_{\alpha}$ has been shown to act as an adjuvant to the development of cytolytic $T$ cells responding to tumor immunization [15]. These findings established the rationale to investigate the effect of TNF $\alpha$ on the: (1) in vivo development of preeffector cells in the tumor-bearing host; (2) in vitro maturation of preeffector cells into effector cells during IVS culture and; (3) in vivo antitumor efficacy of IVS effector cells.

We have previously reported that the TDLN is the site where preeffector cells elicited in response to weakly immunogenic tumors can be reliably retrieved $[4,5]$. For the weakly immunogenic tumors such as MCA 106, preeffector cells in the TDLN are evident as early as 4 days after tumor inoculation and persist out to Day 21. We found that $\mathrm{TNF} \alpha(0.5-8.0 \mu \mathrm{g} /$ animal $)$ given 14 days after tumor inoculation significantly inhibited preeffector cell activity. Preeffector cell activity was assessed by harvesting TDLN cells for IVS culture and measuring their antitumor reactivity in adoptive immunotherapy experiments. There was no apparent relationship between the amount of TNF $\alpha$ administered and the degree of preeffector cell inhibition. In a separate experiment $\mathrm{TNF} \alpha$ administered 7 and 11 days after tumor inoculation was not as effective in inhibiting preeffector cells compared to animals that receive $\mathrm{TNF} \alpha$ on Day 14. One possible explanation is that TNF $\alpha$ inhibited the development of preeffector cells and that earlier TNF $\alpha$ exposure enabled recovery of the tumor-bearing host to develop an immune response to tumor in the TDLN. It was also possible that TNF $\alpha$ inactivated or suppressed already developed preeffector cells within the TDLN.

In order to investigate the latter possibility, $\mathrm{TNF} \alpha$ was added to IVS cultures initiated with established preeffector TDLN cells. TNF $\alpha(10-1000 \mathrm{U} / \mathrm{ml})$ neither suppressed nor enhanced the maturation of preeffector cells into IVS effector cells which were assessed in adoptive immunotherapy experiments. Concentrations of $\mathrm{TNF} \alpha$ in IVS culture were comparable to plasma concentrations achieved in mice (assuming a 2 -ml blood volume per animal) that inhibited preeffector cell activity. These findings would indicate that $\mathrm{TNF} \alpha$ administration in the tumor-bearing host resulted in the inhibition of preeffector cell development within the TDLN.

$\mathrm{TNF} \alpha$ and interferon- $\gamma$ has been reported to synergistically enhance the in vivo antitumor efficacy of TIL and IL-2 therapy [21]. We examined the effect of TNF $\alpha$ administration on the antitumor activity of IVS cells and IL-2. At a nontherapeutic dose of TNF $\alpha$, there was enhanced tumor regression mediated by IVS cells and IL-2. Our laboratory has previously shown that the administration of interferon- $\alpha$ (IFN $\alpha$ ) significantly enhanced the antitumor efficacy of IVS cells in the treatment of MCA 106, but not MCA 203, pulmonary metastases [22]. In that study we found that IFN $\alpha$ pretreatment of MCA 106 tumor cells resulted in increased lysis by IVS cells in a $4-\mathrm{hr}$ chromium release assay which was not evident for the MCA 203 tumor. Similarly, the mechanism by which TNF $\alpha$ enhanced the antitumor function of IVS cells may be to increase the susceptibility of tumor lysis by effector $\mathrm{T}$ cells. Others have reported that specific tumor lysis of cultured tumor targets by TIL in a similar cytotoxicity assay was increased by pretreatment with $\mathrm{TNF} \alpha[21,23]$.

The focus of these studies was to examine the influence of $\mathrm{TNF} \alpha$ in modulating the immune response to tumor in order to improve the therapeutic potential of IVS cell therapy. $\mathrm{TNF} \alpha$ was found to have divergent effects in our experimental model and underscores the multiple sites of interaction where immune modulators may or may not play a beneficial role. At the preeffector cell phase, TNF $\alpha$ was found to inhibit their development within the TDLN. Preliminary studies in our laboratory have indicated that other immune modulators such as IL-1 $\alpha$ or Corynebacterium parvum can augment preeffector cell generation. During the in vitro sensitization phase, TNF $\alpha$ did not alter preeffector cell maturation into therapeutic effector cells. We have previously reported that the antitumor efficacy of IVS cells is dependent upon the concentration of IL-2 used during IVS culture (19). Lower concentrations of IL-2 $(2-10 \mathrm{U} / \mathrm{ml})$ resulted in more potent effector cells compared to higher (100-1000 U/ml) concentrations. The effect of other cytokines within this culture system needs to be further defined. At the effector cell phase, TNF $\alpha$ was found to augment the antitumor reactivity of IVS cells given in conjunction with IL-2, and may be a useful adjunct for 
the therapy of human tumors. Other investigators are actively pursuing the use of sensitized T cells (i.e., TIL) transduced with genes encoding for cytokines such as TNF $\alpha$ in clinical studies (24). The mechanisms by which these cytokines influence $\mathrm{T}$ cell-tumor interactions are an area of active investigation which may help in the development of more effective adoptive immunotherapy approaches.

\section{ACKNOWLEDGMENTS}

The authors thank Bernard A. Fox, Ph.D., for his helpful critique of this manuscript and Deborah Birdsall for her excellent secretarial support. This study was supported in part by a grant from the Boston Foundation, Boston, MA.

\section{REFERENCES}

1. Rosenberg, S. A., and Terry, W. D. Passive immunotherapy of cancer in animals and man. Adv. Cancer Res. 25: 323, 1977.

2. Cheever, M. A., Greenberg, P. D., and Fefer, A. Potential for specific cancer therapy with immune T lymphocytes. J. Biol. Res. Mod. 3: 113, 1984.

3. Shu, S., and Rosenberg, S. A. Adoptive immunotherapy of newly induced murine sarcomas. Cancer Res. 45: 1657, 1985.

4. Shu, S., Chou, T., and Rosenberg, S. A. Generation from tumorbearing mice of lymphocytes with in vivo therapeutic efficacy. $J$. Immunol. 139: 295, 1987.

5. Shu, S., Chou, T., and Sakai, K. Lymphocytes generated by in vivo priming and in vitro sensitization demonstrate therapeutic efficacy against a murine tumor that lacks apparent immunogenicity. J. Immunol. 143: 740, 1989.

6. Chang, A. E., Yoshizawa, H., Sakai, K., and Shu, S. Generation of sensitized $T$ lymphocytes for adoptive immunotherapy. In M. T. Lotze, and O. J. Finn (Eds.), Cellular Immunity and the Immunotherapy of Cancer. UCLA Symposia on Molecular and Cellular Biology. New York: Wiley-Liss, Inc., 1990. Pg. 315-320.

7. Rosenberg, S. A., Lotze, M. T., Muul, L. M., Chang, A. E., Avis, F. P., Leitman, S., Linehan, W. M., Rubertson, C. N., Lee, R. E., Rubin, J. T., Seipp, C. A., Simpson, C. G., and White, D. E. A progress report on the treatment of 157 patients with advanced cancer using lymphokine-activated killer cells and interleukin-2 or high-dose interleukin-2 alone. NEJM 316: 889, 1987.

8. Rosenberg, S. A., Packard, B. S., Aebersold, P. M., Solomon, D., Topalian, S. L., Toy, S. T., Simon, P., Lotze, M. T., Yang, J. C., Seipp, C. A., Simpson, C., Carter, C., Bock, S., Schwartzentruber, D., Wei, J. P., and White, D. E. Use of tumor-infiltrating lymphocytes and interleukin-2 in the immunotherapy of patients with metastatic melanoma. NEJM 319: 1676, 1988.

9. Old, L. J. Tumor necrosis factor (TNF). Science 230: 630, 1985.

10. Asher, A. L., Mule, J. J., Reichert, C. M., Shiloni, E., and Rosenberg, S. A. Studies of the antitumor efficacy of systemically administered recombinant tumor necrosis factor against several murine tumors in vivo. J. Immunol. 138: 963, 1987.

11. Heidenreich, S., Weyers, M., Gong, J-H., Sprenger, H., Nain, M., and Gemsa, D. Potentiation of lymphokine-induced macrophage activation by tumor necrosis factor- $\alpha$. $J$. Immunol. 140, 1511, 1988.

12. Lu, L., Srour, E. F., Warren, D. J., Walker, D., Graham, C. D., Walker, E. B., Jansen, J., and Broxmeyer, H. E. Enhancement of release of granulocyte and granulocyte macrophage colony stimulating factors from phytohemagglutinin stimulated sorted subsets of human $\mathrm{T}$ lymphocytes by recombinant human tumor necrosis factor $-\alpha$. Synergism with recombinant human IFN- $\gamma . J$. Immunol. 141: 201, 1988.

13. Lee, J. C., Truneh, A., Smith, M. F., and Tsang, K. Y. Induction of interleukin 2 receptor (TAC) by tumor necrosis factor in YT cells. J. Immunol. 139: 1935, 1987.

14. Scheurich, P., Thoma, B., Ucer, U., and Pfizenmaier, K. Immunoregulatory activity of recombinant human tumor necrosis factor (TNF)- $\alpha$ : Induction of TNF receptors on human T cells and $\mathrm{TNF} \alpha$ mediated enhancement of $\mathrm{T}$ cell responses. J. Immunol. 138: 1786, 1987.

15. Talmadge, J. E., Phillips, H., Schneider, M., Rowe, T., Pennington, R., Bowersox, O., and Lenz, B. Immunomodulatory properties of recombinant murine and human tumor necrosis factor. Cancer Res. 48: 544, 1988.

16. Wexler, $\mathrm{H}$. Accurate identification of experimental pulmonary metastases. J. Natl. Cancer Inst. 36: 641, 1966.

17. Donohue, J. H., Rosenstein, M., Chang, A. E., Lotze, M. T., Robb, R. J., and Rosenberg, S. A. The systemic administration of purified interleukin 2 enhances the ability of sensitized murine lymphocytes to cure a disseminated syngeneic lymphoma. J. Immunol. 132: 2123, 1984.

18. Cheever, M. A., Greenbery, P. D., Irle, C., Thompson, J. A., Urdal, D. L., Mochizuki, D. Y., Henney, C. S., and Gillis, S. Interleukin 2 administered in vivo induces the growth of cultured $\mathrm{T}$ cells in vivo. $J$. Immunol. 132: 2259, 1984.

19. Chou, T., Chang, A. E., and Shu, S. Generation of therapeutic T lymphocytes from tumor-bearing mice by in vitro sensitization: Culture requirements and characterization of immunologic specificity. J. Immunol. 140: 2453, 1988.

20. Pober, J. S., Gimbrone, M. A., Jr., Lapierre, L. A., et al. Overlapping patterns of activation of human endothelial cells by interleukin 1, tumor necrosis factor and immune interferon. J. Immunol. 137: 893, 1986.

21. Fox, B. A., Spiess, P. J., Kasid, A., Puri, R., Mule, Weber, J. S., and Rosenberg, S. A. In vitro and in vivo antitumor properties of a $\mathrm{T}$ cell clone generated from murine tumor-infiltrating lymphocyles. J. Biwl. Res. Mod. 9: 499, 1990.

22. Vander Woude, D. L., Shu, S., and Chang, A. E. Differential activity of interferon-alpha on the function of sensitized T cells in adoptive immunotherapy. Surgical Forum XLI: 436, 1990.

23. Stotter, H., Wiebke, E. A., Tomita, S., Belldegrun, A., Topalian, S., Kosenberg, S. A., and Lotze, M. 'T. Cytokines alter target cell susceptibility to lysis: II. Evaluation of tumor infiltrating lymphocytes. J. Immunol. 142: 1767, 1989.

24. Rosenberg, S. A., Aebersold, P., Cornetta, K., Kasid, A., Morgan, R. A., Moen, R., Karson, E. M., Lotze, M. T., Yang, J. C., Topalian, S. L., Merino, M. J., Culver, K., Miller, A. D., Blaese, K. M., and Anderson, W. F. Gene transfer into humans-immunotherapy of patients with advanced melanoma, using tumor-infiltrating lymphocytes modified by retroviral gene transduction. NEJM 323: 570, 1990. 